Document downloaded from:

http://hdl.handle.net/10251/150360

This paper must be cited as:

Herraiz-Cardona, I.; Ortega Navarro, EM.; Vázquez-Gómez, L.; Pérez-Herranz, V. (2011). Electrochemical characterization of a $\mathrm{NiCo} / \mathrm{Zn}$ cathode for hydrogen generation. International Journal of Hydrogen Energy. 36(18):11578-11587. https://doi.org/10.1016/j.ijhydene.2011.06.067

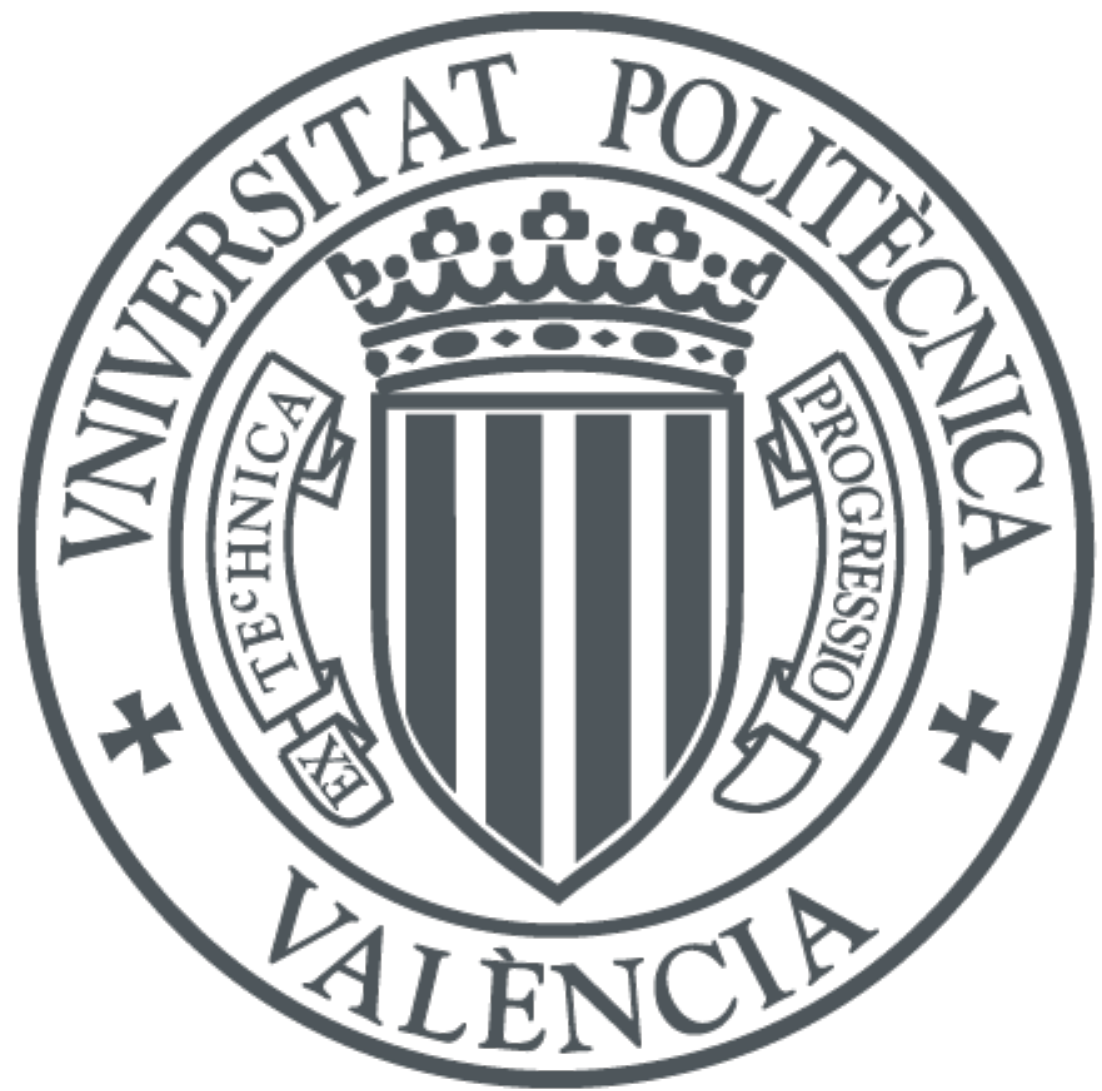

The final publication is available at

https://doi.org10.1016/j.ijhydene.2011.06.067

Copyright PERGAMON-ELSEVIER SCIENCE LTD

Additional Information 


\title{
Electrochemical Characterization of a NiCo/Zn Cathode for Hydrogen Generation
}

\author{
I. Herraiz-Cardona ${ }^{\mathrm{a}}$, E. Ortega ${ }^{\mathrm{a}}$, L. Vázquez-Gómez ${ }^{\mathrm{b}}$, V. Pérez-Herranz ${ }^{\mathrm{a}^{*}}$ \\ ${ }^{a}$ Ingeniería Electroquímica y Corrosión (IEC). Departamento de Ingeniería Química y \\ Nuclear. Universitat Politècnica de València. Camino de Vera s/n. 46022 Valencia, \\ Spain. \\ ${ }^{\mathrm{b}}$ IENI CNR, Corso Stati Uniti 4, 35127 Padova, Italy \\ *Corresponding author. Tel.: +34-96-3877632; fax: +34-96-3877639; \\ e-mail address: vperez@iqn.upv.es (V. Pérez-Herranz)
}

\begin{abstract}
Hydrogen is considered to be the most promising candidate as a future energy carrier. One of the most used technologies for the electrolytic hydrogen production is alkaline water electrolysis. However, due to the high energy requirements, the cost of hydrogen produced in such a way is high.

In continuous search to improve this process using advanced electrocatalytic materials for the hydrogen evolution reaction (HER), high area $\mathrm{NiCo} / \mathrm{Zn}$ electrodes were prepared on AISI 304 stainless steel substrates by electrodeposition. After preparing, the alloys were leached of to remove part of the zinc and generate a porous layer (type Raney electrodes). The presence of a thin Ni layer between the substrate and the Raney coating favour the adherence of the latter. The porous $\mathrm{NiCo} / \mathrm{Zn}$ electrode was characterized by SEM, EDX, confocal laser microscopy, and electrochemical impedance spectroscopy. HER on this electrode was evaluated in $30 \mathrm{wt} . \% \mathrm{KOH}$ solution by means of polarization curves, hydrogen discharge curves, and galvanostatic tests. Results show that the developed electrode presents a most efficient behaviour for HER when comparing with the smooth Ni cathode. The high electrode activity was mainly attributed to the high surface area of the developed electrode.
\end{abstract}


Keywords: porous Ni electrodes, HER, EIS, nickel-cobalt alloys 


\section{Introduction}

Hydrogen is considered an ideal energy carrier that can be an alternative to fossil fuels. It is a clean and fully recyclable substance with a practically unlimited supply and has all the criteria considered for an alternative energy source [1-3]. The electrochemical production of hydrogen by alkaline water electrolysis is one of the most promising methods with great potential of using renewable energy sources, such as solar energy $[4,5]$. Also it represents an environmentally friendly technology for production of high purity hydrogen $[1,6]$. However, the high energy consumption of alkaline water electrolysis retrains its large-scale application at present. In order to make this technique more efficient and economical, both the decrease of the overpotentials of electrode reactions and the selection of inexpensive electrode materials with good electrocatalytic activity are needed. The electrode activity can be enlarged by increasing the real surface area and/or the intrinsic activity of the electrode material [7]. For this purpose, the most important and most studied electrode material is nickel, its alloys and compounds [815]. Nickel type Raney coatings are usually employed as the cathodic material for HER, due to its capability to generate high currents per unit of external surface. This property is mainly based in its very high internal area originated in its cracks formations $[8,16]$. In addition to the electrocatalytic activity, the other important parameters for selecting a material for electrolysis are its stability during long-term electrolysis and the corrosion resistance in the operation solution, because, during shut down periods, electrode materials can corrode and, as a result, lose their activity as well as decrease their life time. Divisek et al. [17] showed that the catalytic activity of the Raney-Nickel coatings is deteriorated with long-term electrolysis due to changes of the reaction mechanism, deposition of trace metals and/or dissolution of the catalyst components. 
In order to obtain an electrochemically more stable electrode and provide adequate corrosion protection, it is necessary to use a thin nickel coating under the Raney-Nickel deposits [14]. The presence of this nickel layer considerably diminishes the disintegration of the Raney type coating during the continuous operation in strong basic media. Moreover, the nickel layer acts as a physical barrier for the access of the aggressive electrolyte through the porous surface to the substrate material, improving the corrosion properties of the material $[14,15]$. According to the last point, in a previous work [18] different $\mathrm{Ni} / \mathrm{Zn}$ and $\mathrm{NiCo} / \mathrm{Zn}$ electrode materials where morphologically characterized by electrochemical impedance spectroscopy. The aim of the present work is to carry out a complete electrochemical characterization of $\mathrm{NiCo} / \mathrm{Zn}$ Raney type electrodes for HER. The porous $\mathrm{Ni}-\mathrm{Co} / \mathrm{Zn}$ electrodes synthesized were characterized by SEM, EDX, confocal laser microscopy, and electrochemical impedance spectroscopy (EIS). Their activity towards hydrogen evolution was assessed by recording polarization curves, hydrogen discharge curves, and series of galvanostatic tests, simulating the conditions in the normal operation of an alkaline electrolyser. 


\section{Experimental}

\subsection{Preparation of electrodes}

The metallic coatings were deposited on an AISI 304 stainless steel cylindrical substrate, embedded in Teflon, leaving a cross-sectional available area of $0.5 \mathrm{~cm}^{2}$. AISI 304 stainless steel as substrate material was mainly chosen due to its good mechanical and corrosion resistance at relatively low cost.

Before the electrodeposition experiments, the stainless steel substrate was mechanically polished with emery paper down to 4000 grit, next it was degreased for 1 minute with 25 wt. $\% \mathrm{NaOH}$ at $90{ }^{\circ} \mathrm{C}$, immersed in $\mathrm{HCl} 18$ wt.\% during 1 minute, and anodically treated in $70 \mathrm{wt} . \% \mathrm{H}_{2} \mathrm{SO}_{4}$ at $108 \mathrm{~mA} \mathrm{~cm}^{-2}$ for 3 minutes. Then the substrate surface was struck at $-27 \mathrm{~mA} \mathrm{~cm}{ }^{-2}$ in a Wood's nickel solution $\left(240 \mathrm{~g} \mathrm{~L}^{-1} \mathrm{NiCl}_{2}, 120\right.$ $\mathrm{mL} \mathrm{L}^{-1} \mathrm{HCl}$ ) for 5 minutes, in order to produce a thin, adherent deposit of nickel which serves as a base for the subsequent electrodeposition. Between each treatment the electrode was rinsed with distilled water.

$\mathrm{Ni}-\mathrm{Co} / \mathrm{Zn}$ alloy depositions were performed galvanostatically, at a current density of $-50 \mathrm{~mA} \mathrm{~cm}^{-2}$, from a modified Watts Bath (MWB) in which $\mathrm{NaCl}$ was substituted by $\mathrm{NiCl}_{2}$. The bath composition is detailed in Table 1 . The reagents used for electrolyte preparation were of chemical grade and were no subjected to an additional purification. Distilled water was used to prepare electrolytes. The electrolyte temperature was kept at $50^{\circ} \mathrm{C}$ in all the electrodeposition experiments.

Electrodepositions were carried out in a thermostated one-compartment cell made of Pyrex glass with a Teflon cover having adequate holes to lodge the electrodes and entrances to add reagents to the bath. The solution inside the cell had an initial volume of $50 \mathrm{~mL}$ and was stirred by means of a magnetically driven stirrer. The counter electrode was a large-area graphite electrode of high purity. The reference electrode was 
a commercially available silver-silver chloride $(\mathrm{Ag}-\mathrm{AgCl})$ electrode with $3 \mathrm{M}$ potassium chloride $(\mathrm{KCl})$ solution. The experiments were accomplished by using an AUTOLAB PGSTAT302N potentiostat/galvanostat.

After the electrodeposition, the electrodes were treated in $6 \mathrm{M} \mathrm{NaOH}$ at $50{ }^{\circ} \mathrm{C}$ during 48 hours. Treatment in alkali dissolves a percentage of the electrodeposited zinc producing a porous nickel layer of high surface area $[12,13]$. The structures, morphologies and compositions of the $\mathrm{Ni}-\mathrm{Co} / \mathrm{Zn}$ alloys were examined by means of an OLYMPUS LEXT OLS3100-USS confocal laser scanning microscope, and a JEOL JSM-3600 scanning electron microscope (SEM) coupled with an Energy-Dispersive XRay (EDX) Spectrometer.

\subsection{Electrochemical measurements}

The developed electrodes were characterized by means of polarization curves, electrochemical impedance spectroscopy, hydrogen discharge curves, and galvanostatic tests. All these tests were performed in oxygen free $30 \mathrm{wt} \% \mathrm{KOH}$ solutions, which were achieved by bubbling $\mathrm{N}_{2}$ for $15 \mathrm{~min}$ before the experiments.

Polarization curves were potentiodynamically recorded from $-1.60 \mathrm{~V}$ vs $\mathrm{Ag} / \mathrm{AgCl}\left(-1.40 \mathrm{~V}\right.$ vs SHE) up to the equilibrium potential, at a scan rate of $1 \mathrm{mV} \mathrm{s}^{-1}$, and at six different temperatures: $30,40,50,60,70$ and $80^{\circ} \mathrm{C}$. Before the tests, the working electrode was held at $-1.60 \mathrm{~V}$ vs $\mathrm{Ag} / \mathrm{AgCl}(-1.40 \mathrm{~V}$ vs $\mathrm{SHE})$ in the same solution, in order to reduce the oxide film existing on the porous surface electrode layer, for the time needed to establish reproducible polarization diagrams.

EIS measurements were performed after obtaining the polarization curves. Alternating current impedance measurements were carried out at different cathodic overpotentials, and at the following temperatures: 30,50 , and $80{ }^{\circ} \mathrm{C}$. The measurements 
were made in the frequency range of $10 \mathrm{kHz}$ to $3 \mathrm{mHz}$. Ten frequencies per decade were scanned using a sinusoidal signal of $10 \mathrm{mV}$ peak-to-peak. The complex nonlinear least square (CNLS) fitting of the impedance data was carried out with the Zview 3.0 software package.

In order to obtain the hydrogen discharge curves, a progressively increasing voltage was applied, starting from $0 \mathrm{~V}$ between the anode (smooth $\mathrm{Ni}$ ) and cathode (working electrode) and going up to $-3 \mathrm{~V}$. With the aid of these curves, the minimum discharge potentials were determined experimentally for each electrode pair.

Finally, the galvanostatic experiments were carried out at three different applied current densities of 20, 50 and $100 \mathrm{~mA} \mathrm{~cm}^{-2}$ and at six different temperatures: 30, 40, $50,60,70$ and $80{ }^{\circ} \mathrm{C}$, during 1 hour.

The electrochemical measurements were carried out in an electrochemical cell developed by the Dpto. Ingeniería Química y Nuclear of the Polytechnic University of Valencia [19]. It is a three-electrode cell that allows monitoring the volume of gas generated at the anode and the cathode. Also, this system has a heating circuit to control the temperature. A Luggin capillary, whose tip was set at a distance of about $1 \mathrm{~mm}$ from the surface of the working electrodes, was used to minimize the variations due to $j R$ drop in the electrolytes (see Fig. 1). 


\section{Results and discussion}

Stainless steel substrates have a thin naturally protective oxide film which forms quite quickly when exposed to air, for this reason these substrates are difficult to coat with adherent electrodeposits [20]. To prevent this problem, between the pre-treatment steps the substrate material was quickly rinsed and immersed in the bath of the following step, in order to avoid the contact with air. Furthermore, the Wood's nickel strike produces a thin, adherent deposit of nickel which serves as a base for subsequent coatings. This Ni layer enhances the activity and stability of the electrode material for alkaline water electrolysis [14]. NiCo/Zn coatings deposited electrolytically show good adhesion to the AISI 304 stainless steel substrate and good physical stability.

Figure 2 shows a micrograph of the developed coatings, obtained using a confocal laser scanning microscope. The cracks considerably enlarge the surface area of the electrode. Moreover, the cracked surface can increase the activity of HER. Hence, the energy requirements (overpotential) to obtain a specific hydrogen production (current density) can be diminished [21]. The $\mathrm{NiCo} / \mathrm{Zn}$ layer, after the leaching treatment, contains about 77 wt. $\%$ of nickel, 19 wt. $\%$ of zinc, and 3 wt. $\%$ of cobalt. Therefore, the chemical composition analysis revealed that after the leaching treatment, there is still a high percentage of zinc present in the coatings, which corresponds to the zinc occluded down to a NiCo layer.

In order to investigate the catalytic activity of the prepared layers, Tafel linear polarization measurements were performed in $30 \mathrm{wt} \% \mathrm{KOH}$ solutions, and the corresponding electrochemical parameters (Tafel slope, exchange current density, transfer coefficient) were derived from the recorded curves. Fig. 3 shows a set of Tafel curves recorded at different temperatures on the catalyst layer investigated. The curves performed on commercial smooth $\mathrm{Ni}$ electrode were also included to compare the 
obtained results. The curves were corrected with respect to the reversible HER potential at the given conditions and for the $j R$-drop. The Tafel curves obtained for the $\mathrm{NiCo} / \mathrm{Zn}$ layer (Fig. 3) show a classical Tafelian behaviour, indicating that the HER on this electrode is a purely kinetically controlled reaction described by the Tafel equation [22, 23]:

$$
\eta=a+b \log j
$$

where $\eta(\mathrm{V})$ represents the applied overpotential, $j\left(\mathrm{~A} \mathrm{~cm}^{-2}\right)$ the resulting (measured) current density, $b\left(\mathrm{~V}\right.$ decade $\left.^{-1}\right)$ the Tafel slope, and $a(\mathrm{~V})$ is the intercept related to the exchange current density $j_{0}\left(\mathrm{~A} \mathrm{~cm}^{-2}\right)$ through the equation:

$$
a=(2.3 R T) /\left(\beta n_{e} F\right) \times \log j_{0} .
$$

The other parameter of interest is $\beta$, the symmetry factor, which can be calculated from the Tafel slope

$$
b=-(2.3 R T) /\left(\beta n_{e} F\right),
$$

where $n_{e}$ represents the number of electrons exchanged, $F\left(=96,485 \mathrm{C} \mathrm{mol}^{-1}\right)$ is the Faraday constant, and $R\left(=8.314 \mathrm{~J} \mathrm{~mol}^{-1} \mathrm{~K}^{-1}\right)$ is the gas constant. Since the $\mathrm{NiCo} / \mathrm{Zn}$ curves in Fig. 3 do not show any significant change in the Tafel slope, the same HER reaction mechanism should be valid through the entire overpotential region investigated. The values of the kinetic parameters are reported in Table 2. The mechanism of HER in alkaline solution involves the formation of an adsorbed hydrogen atom (adatom) intermediate, $M H_{a d s}$ (Volmer reaction, Eq. (4)), the electrodic desorption of hydrogen into solution (Heyrovsky reaction, Eq. (5)) and/or a chemical desorption by the combination of two adatoms (Tafel reaction, Eq. (6)):

$$
\begin{aligned}
& \mathrm{H}_{2} \mathrm{O}+\mathrm{M}+e^{-} \rightarrow \mathrm{MH}_{a d s}+\mathrm{OH}^{-} \\
& \mathrm{H}_{2} \mathrm{O}+\mathrm{MH}_{a d s}+e^{-} \rightarrow \mathrm{H}_{2}+\mathrm{M}+\mathrm{OH}^{-}
\end{aligned}
$$




$$
M H_{a d s}+M H_{a d s} \rightarrow H_{2}+2 M
$$

where $M$ is a free site on the metal surface and $M H_{a d s}$ is the metal surface occupied by hydrogen adatoms. When the mechanism is determined from the rate-determining step (rds) of a multi-step reaction, the Tafel slope plays an important role in estimating the mechanism $[24,25]$. It has been widely accepted that the value of the charge-transfer coefficient, $\alpha$, depends on the rds for multi-step reactions [12, 26-29]. Note that for the Volmer step the symmetry factor, $\beta$, is equal to the transfer coefficient, $\alpha$ (i.e. $\alpha=\beta$ ), while for the Heyrovsky step the transfer coefficient is equal to $\alpha=1+\beta[23,30]$. According to the general model for the HER mechanism, when the rds is Eq. (4), or Eq (4) coupled with Eq (5), or Eq (4) coupled with Eq (6), the value of $\alpha$ is 0.5. Therefore, the Tafel slope becomes $120 \mathrm{mV} \mathrm{dec}^{-1}$ at $30^{\circ} \mathrm{C}$, and $140 \mathrm{mV} \mathrm{dec}^{-1}$ at $80{ }^{\circ} \mathrm{C}$. Other possibilities are $\alpha=1.5$ and $b=40 \mathrm{mV} \mathrm{dec}{ }^{-1}$ at $30{ }^{\circ} \mathrm{C}$, when Eq. (5) is rds; and $\alpha=2$ and $b=30 \mathrm{mV} \mathrm{dec}-1$ at $30{ }^{\circ} \mathrm{C}$, when Eq. (6) is the rds [31-33]. Here, the Tafel slope ranges between $80 \mathrm{mV} \mathrm{dec}-1$ and $120 \mathrm{mV} \mathrm{dec}^{-1}$ at 30 and $80{ }^{\circ} \mathrm{C}$, respectively, and the $\alpha=\beta$ values are close to 0.5 for the $\mathrm{NiCo} / \mathrm{Zn}$ catalyst (see Table 2).

In contrast to the behaviour reported for the developed electrodes, the polarization curves recorded on the smooth $\mathrm{Ni}$ electrode (Fig. 3) display two potentialdependent regions related to the HER. As depicted in Table 2, the Tafel slopes decrease from higher values at overpotentials less cathodic than approximately $-200 \mathrm{mV}, b_{l \eta}$, to lower values at more cathodic overpotentials, $b_{h \eta}$. The existence of two Tafel regions has already been reported in literature on Ni-based catalysts [10, 26, 32, 34-37]. At low cathodic overpotentials the Tafel slopes $\left(b_{l \eta}\right)$ are higher than $120 \mathrm{mV} \mathrm{dec}^{-1}$ at $30{ }^{\circ} \mathrm{C}$, 
which may indicate the presence of some oxides on the surface of the Ni electrode [22, 34].

In Table 2 it is also reported the overpotential values at a fixed current density of $-100 \mathrm{~mA} \mathrm{~cm}{ }^{-2}, \eta_{100}$. This parameter gives an indication on the amount of energy (overpotential) that has to be invested to produce a fixed amount of hydrogen. The developed electrode is characterized by higher exchange current density, $j_{0}$, and lower hydrogen overpotential, $\eta_{100}$, compared with the smooth $\mathrm{Ni}$ electrode, thereby indicating an improvement of electrocatalytic activity.

The information obtained from the Tafel polarization data demonstrate that the investigated Ni-based catalyst is very active for the HER, showing a higher catalytic activity than the smooth Ni electrode. However, since the Tafel curves are normalized to the geometric area of the catalyst and not to the real electrochemical area, the results discussed above cannot offer a definite conclusion if the observed electrocatalytic activity is a result of only an increased surface area of the catalysts, or if an improvement in the intrinsic (electronic) electrocatalytic properties of the catalyst material is also a contributing factor. Therefore, in order to obtain information on the intrinsic activity of the investigated layer in the HER, the curves presented in Fig. 3 should be normalized to the real electrochemically active surface area. In this work, an EIS technique has been proposed as the most appropriate to determine the real surface area in electrochemical systems, as previously used in literature [38-40].

EIS measurements were made at different selected overpotentials of the previously obtained polarization curves: $\eta_{l}$, corresponding to the equilibrium potential, $0 \mathrm{mV} ; \eta_{2}$, a cathodic overpotential at which it is not manifested the hydrogen evolution; $\eta_{3}$, an overpotential at which the hydrogen production takes place at a very low rate; and $\eta_{4}$, at which hydrogen is vigorously generated. Figure 4 shows the effect of both 
applied cathodic overpotential (Fig. 4.a) and temperature (Fig. 4.b) on the Nyquist plots of the impedance of the $\mathrm{NiCo} / \mathrm{Zn}$ electrode. The EIS spectra recorded reveals the presence of two overlapped semicircles (i.e. two different time constants), the first one at high frequencies (HF), and the second one at low frequencies (LF). From Fig. 4 it is clear that the diameter of both semicircles considerably decreases with both the cathodic overpotential and temperature, indicating that both semicircles are related to the electrode kinetics [13]. As the overpotential increases, the LF semicircle in the impedance plots becomes smaller and smaller, even disappears at very high cathodic overpotentials. This is due to the fact that the adsorption process is facilitated and the charge-transfer process dominates the impedance response as the potential increases. Therefore, according to the results obtained from both Tafel and EIS studies, one can assume that the Volmer-Heyrovsky mechanism must control the HER on that electrode.

As it was discussed in a previous paper [18], the two-time constants parallel (2TP) electric equivalent circuit (Fig. 5), proposed by Armstrong and Henderson [41], properly models and describes the AC response of the NiCo/Zn layer. The $2 \mathrm{TP}$ model reflects the response of a HER system characterized by two time constants, the first time constant, $\tau_{1}\left(C P E_{1}, R_{1}\right)$, related to the charge transfer kinetics, and the second one, $\tau_{2}$ $\left(C_{2}, R_{2}\right)$, related to the hydrogen adsorption $[13,22,42,43]$. Table 3 shows the best-fit estimates of the different 2TP EEC parameters obtained from the impedance measurements on the $\mathrm{NiCo} / \mathrm{Zn}$ electrode at $80^{\circ} \mathrm{C}$. The average double layer capacitances, $C_{1}$, for the catalytic coatings were determined using the relation suggested by Brug et al. [44]:

$$
C_{1}=\left[Q_{1} /\left(R_{S}^{-1}+R_{1}^{-1}\right)^{\left(1-n_{1}\right)}\right]^{1 / n_{1}}
$$

where $Q_{1}$ and $n_{1}$ are the $C P E_{1}$ constant and exponent, respectively; $R_{S}$ is the solution resistance; and $R_{l}$ the HER charge transfer resistance. Considering a value of $20 \mu \mathrm{F} \mathrm{cm}-$ 
${ }^{2}$ for the double layer capacitance, $C_{d l}$, of a smooth nickel surface, used earlier in the literature $[12,26]$, the real active surface area, in terms of surface roughness factor $\left(R_{f}\right)$, may be estimated by comparing the $C_{d l}$ related to the HER charge-tranfer kinetics of porous/rough and smooth electrodes [45]. The plots of the electrode surface roughness factor as function of the HER overpotential are displayed in Fig. 6. As it is clear from Fig. 6, the values of $R_{f}$ decrease when increasing the cathodic potential, up to a convergence value of about 700 . This may be due to a blockage of a fraction of the inner surface of the electrode during HER due to gas bubbles shielding, and hence not electrochemically accessed by the electrolyte [38, 46-48], and an interface shifting as the electrode surface is not real flat. The $R_{f}$ data allows us to evaluate the relative intrinsic catalytic activity of the investigated catalyst, by subtracting the effect of the surface area. For this purpose, the Tafel plots were normalized to the true surface area by dividing the curves by the corresponding surface roughness factor, see Fig. 7. As depicted in Fig.7, at high overpotentials the current density of the smooth Ni electrode is lower than that reported for the $\mathrm{NiCo} / \mathrm{Zn}$ layer. Although there is a high percentage of $\mathrm{Zn}$ in the obtained coating, the superficial catalytic electrode layer is mainly composed of $\mathrm{Ni}$, with a little percentage of $\mathrm{Co}$, due to the fact that superficial $\mathrm{Zn}$ is rapidly leached out in the alkaline media used. Moreover, as it was shown in a earlier work [49] the presence of $\mathrm{Co}$ in this composition range does not manifest the synergism among the catalytic properties of nickel (low hydrogen overpotential) and of cobalt (high hydrogen adsorption). According to this, the developed electrode can be considered as a pure $\mathrm{Ni}$ layer. Therefore, the increase in the catalytic activity on the $\mathrm{NiCo} / \mathrm{Zn}$ electrode at high overpotentials can be explained by a different magnitude of the standard adsorption energy on the substrates analyzed. In the case of the smooth Ni electrode subjected to mechanical polishing the surface layer presents some degree of amorphization, which 
implies a disordered surface structure. On the contrary, the electrodes obtained by electrodeposition are highly crystalline and the surfaces have a more ordered structure. As a result, the polished nickel electrode shows a lower hydrogen equilibrium surface coverage than the macroporous electrodeposits, which affects the hydrogen production at most cathodic overpotentials [37].

In order to evaluate the suitability of the developed cathode for the most economical electrolysis process, both current-cell potential curves (hydrogen discharge curves) and galvanostatic tests have been carried out. All these tests where performed in the P200803389 cell [19]. It is a thermostated three-electrode cell that allows monitoring the volume of gas generated at the anode and the cathode. Figure 8 shows the hydrogen discharge curves obtained using as cathodes both the $\mathrm{NiCo} / \mathrm{Zn}$ and the smooth Ni electrodes in $30 \mathrm{wt} . \% \mathrm{KOH}$ solution. After the discharge of gasses, there is a rapid increase in the current with increasing applied voltage, because of the evolution of hydrogen at the cathode and oxygen at the anode. As seen in Fig.8, the discharge of gasses starts at lower potential for the $\mathrm{NiCo} / \mathrm{Zn}$ electrode, and the current passing through the solution is larger with this cathode, compared with the smooth Ni cathode, at all potentials. The minimum hydrogen discharge potentials $\left(E_{\text {exp }}\right)$, given in Table 4 , were experimentally determined by extrapolating the linear part of the hydrogen discharge curves (between 2 and $3 \mathrm{~V}$ ) to the zero current, as described elsewhere [50]. The $E_{\exp }$ values decrease with temperature due to the increased conductivity of the electrolyte and higher electrode activities. The reversible discharge potential for water splitting $\left(E_{r e v}\right)$ also reduces with an increase in operating temperature as given by the relation $[51,52]$ :

$$
E_{\text {rev }}(T / K)=1.5184-1.5421 \cdot 10^{-3} \cdot T+9.523 \cdot 10^{-5} \cdot T \cdot \ln T+9.84 \cdot 10^{-8} \cdot T^{2}
$$


The difference between the measured and theoretical calculated values of these systems $\left(E_{\text {exp }}-E_{r e v}\right)$ can be taken to be the experimental overpotential that represents the voltage in excess of the thermodynamic voltage, required to overcome the losses in the cell $(\eta)$. As it is clear from the data in Table 4, the obtained overpotential for the $\mathrm{NiCo} / \mathrm{Zn}$ coating is lower than that registered for the smooth Ni electrode. This reduction can be attributed to the lower cathodic overpotential associated with the reaction kinetics (electrode polarization effects) in the synthesized electrode with respect to the smooth commercial $\mathrm{Ni}$ electrode. It is also seen in Table 4 that the cathode overpotentials remain almost constant with the temperature for both electrodes.

When temperature is considered it is accurate to use the higher heating value voltage $\left(E_{H H V}\right)$ for efficiency calculation [52]. $E_{H H V}$ corresponds to the heat content of the dry product gases with respect to the liquid water at $25^{\circ} \mathrm{C}$. Therefore,

$$
\varepsilon=\frac{E_{H H V}}{E_{\text {cell }}} .
$$

where $\varepsilon$ is the energy efficiency, and $E_{\text {cell }}$ is the cell voltage.

The absolute temperature dependence of $E_{H H V}$ can be given by the relation $[52,53]$ :

$$
E_{H H V}(T / K)=1.4146+2.205 \cdot 10^{-4} \cdot T+1.0 \cdot 10^{-8} \cdot T^{2}
$$

$E_{H H V}$ increases slightly with temperature, taking a value of $1.494 \mathrm{~V}$ at $80{ }^{\circ} \mathrm{C}$. In order to determine the maximum efficiency of the hydrogen evolution process, the minimum hydrogen discharge potentials, $E_{\exp }$ shown in Table 4 , can be used as the cell voltage $\left(E_{\text {cell }}\right)$ in Eq. 9. As it is shown in Fig. 9, higher energy efficiencies for a hydrogen production are obtained at higher operating temperature conditions, because of an increase in the mobility of the molecules and ions. Moreover, the $\mathrm{NiCo} / \mathrm{Zn}$ electrode efficiency is higher than that reported for the smooth $\mathrm{Ni}$ electrode, due to the improvement in the catalytic activity of the developed electrode. 
Galvanostatic tests have been carried out in order to verify the performance behaviour of these alloys in long duration experiences for the HER, at different current densities and temperatures. Fig 10.a reports the cell voltage for a temperature of $50{ }^{\circ} \mathrm{C}$ at different current densities. Notwithstanding the small potential oscillation, the registered cell voltage (between anode and cathode) can be considered to be rather stable. It can be appreciated an increase in the cell voltage with the current density. The inverse effect in the cell voltage is obtained when the temperature is increased for a same current density (50 $\mathrm{mA} \mathrm{cm}^{-2}$, in Fig. 10.b). On the other hand, as it is shown in the histograms of Figure 10, the hydrogen production remains practically constant with the variation in temperature, increasing directly with the current density applied. It has not been recorded loses in the catalytic activity, unexpected increases in the cell potential for a same current density applied, during the application of the set of galvanostatic tests, consolidating the stability of the Raney-Nickel coatings developed on smooth Nickel deposits.

The energy requirements for the electrolytic hydrogen evolution process are calculated using the relation:

$$
Q=\frac{I \cdot U \cdot t}{\text { mole } H_{2}}
$$

where Q is the energy consumption per one mole of hydrogen evolved $\left(\mathrm{kJ} \mathrm{mole}^{-1}\right)$, I is the absolute applied current in $\mathrm{A}, \mathrm{U}$ is the cell voltage in $\mathrm{V}$ and $\mathrm{t}$ is the time in seconds. To obtain the correct number of hydrogen moles, the hydrogen pressure was determined as follows:

$$
P_{H_{2}}=P_{a t m}+\rho(T) g h-P_{v}(T)
$$

where $P_{a t m}$ is the atmospheric pressure, $\rho(T)$ is the mass density of a 30 wt. $\% \mathrm{KOH}$ solution, $g$ is the gravitational acceleration, $h$ is the height difference between the liquid 
levels of the cathodic and central compartments, and $P_{v}(T)$ is the water saturation pressure in $30 \mathrm{wt} . \% \mathrm{KOH}$ solutions. In this way, the moles of evaporated water at the temperature conditions can be subtracted from the measured volume in the cathodic compartment of the voltammeter. The obtained results are presented in Fig. 11 as a three-dimensional diagram of energy consumption. In Fig. 11 it is shown an expected type of dependence: increase of the energy consumption with the increase of current density. On the other hand, the energy requirement decreases with increasing temperature. In principal, that means the higher the temperature the higher the reaction rate, thus the lower voltage requested for a certain current density. As it is clearly shown in Fig. 11, energy consumption of the electrolysis cell decreases for about $20 \%$ using the $\mathrm{NiCo} / \mathrm{Zn}$ catalyst coating as cathode, with respect to the commercial smooth $\mathrm{Ni}$ electrode.

The energy efficiency, $\varepsilon$, was also determined for each point of the surface plot of Fig.11, obtaining Fig.12. As it is shown, the efficiency of the electrolysis is inversely proportional to the cell potential [54]. Therefore, as the cell potential increases with the electrolysis current, it can be seen that the efficiency slightly decreases at increasing $\mathrm{H}_{2}$ production. The obtained efficiencies of the unity electrolysis cell can not be compared to that reported in literature, due to the specific cell geometry. Nevertheless, it has been observed an improvement in the energy efficiency of about 10-35\% when comparing with the commercial nickel electrode. 


\section{Conclusions}

$\mathrm{NiCo} / \mathrm{Zn}$ stainless steel-based electrodes, produced by electrodeposition, were characterized both morphological and electrochemically for hydrogen evolution reaction in alkaline media, showing significant electrocatalytic effects. Polarization curves and AC electrochemical impedance spectroscopy (EIS) measurements allowed us to determine the mechanism and kinetics of the HER. It was shown that the HER on $\mathrm{NiCo} / \mathrm{Zn}$ catalyst is controlled by the Volmer-Heyrovsky mechanisms. Values for exchange current densities were in the range of $10^{-3}-10^{-2} \mathrm{~A} \mathrm{~cm}^{-2}$. EIS results suggest that the improvement in the HER electrocatalytic activity observed for the $\mathrm{NiCo} / \mathrm{Zn}$ catalyst is mainly attributed to the increased surface area. The decrease of surface roughness factor $\left(R_{f}\right)$ values with rise of cathodic overpotential was ascribed to the occlusion of pores by gas bubbles due to the intensification of the HER at more negative overpotential.

From the galvanostatic tests it has been pointed out that energy savings per mass unit of electrolytically evolved hydrogen from alkaline aqueous solutions on the $\mathrm{NiCo} / \mathrm{Zn}$ electrode, can be beyond $20 \%$ in some cases, compared with the standard nickel electrodes. Moreover, $\mathrm{NiCo} / \mathrm{Zn}$ electrode shows a most efficient behaviour than that obtained for the smooth pure Ni electrode.

The electrocatalytic achievement and obtained stability of the $\mathrm{NiCo} / \mathrm{Zn}$ electrode, appears valuable in the view of the significant energy savings, which is relevant for the possible use in industrial applications. 


\section{Acknowledgments}

Isaac Herraiz-Cardona is grateful to the Ministerio de Ciencia e Innovación (Spain) for a postgraduate grant (Ref. AP2007-03737). This work was supported by Generalitat Valenciana (Project PROMETEO/2010/023) 


\section{REFERENCES}

[1] Veziroglu TN, Barbir F. Hydrogen - the wonder fuel. Int J Hydrogen Energy 1992;17:391-404.

[2] Elosta WB, Veziroglu TN. Solar hydrogen energy system for a Libyan coastal county. Int J Hydrogen Energy 1990;15:33-44.

[3] Bockris JO, Veziroglu TN. A solar-hydrogen economy for USA. Int J Hydrogen Energy $1983 ; 8: 323-340$

[4] Hug W, Divisek J, Mergel J, Seeger W, Steeb H. Highly efficient advanced alkaline electrolyzer for solar operation. Int J Hydrogen Energy 1992;17:699-705.

[5] Garciaconde AG, Rosa F. Solar hydrogen-production - A Spanish experience. Int J Hydrogen Energy 1993;18:995-1000.

[6] Hydrogen Energy and Fuel Cells - A vision of our future. European Commission, EUR 20719 EN; Luxembourg, 2003, 1-36.

[7] Lasia A. Hydrogen Evolution. In: Vielstich W, Lamm A, Gasteiger HA, editors. Handbook of fuel cell technology, John Wiley and Sons Ltd; 2003, p. 416-440.

[8] Sheela G, Pushpavanam M, Pushpavanam S. Zinc-nickel alloy electrodeposits for water electrolysis. Int J Hydrogen Energy 2002;27:627-633.

[9] Rommal HEG, Moran PJ. Time-dependent energy efficiency losses at nickel cathodes in alkaline water electrolysis systems. J Electrochem Soc 1985;132:325329.

[10] Lasia A, Rami A. Kinetics of hydrogen evolution on Nickel electrodes. J Electroanal Chem 1990;294:123-141.

[11] Choquette Y, Brossard L, Lasia A, Menard H. Investigation of hydrogen evolution on Raney-Nickel composite-coated electrodes. Electrochim Acta 1990;35:12511256.

[12] Chen LL, Lasia A. Study of the kinetics of hydrogen evolution reaction on NickelZinc alloy electrodes. J Electrochem Soc 1991;138:3321-3328. 
[13] Birry L, Lasia A. Studies of the hydrogen evolution reaction on Raney nickelmolybdenum electrodes. J Appl Electrochem 2004;34:735-749.

[14] Solmaz R, Kardas G. Hydrogen evolution and corrosion performance of NiZn coatings. Energy Conv Manag 2007;48:583-591.

[15] Crnkovic FC, Machado SAS, Avaca LA. Electrochemical and morphological studies of electrodeposited Ni-Fe-Mo-Zn alloys tailored for water electrolysis. Int J Hydrogen Energy 2004;29:249-254.

[16] Suffredini HB, Cerne JL, Crnkovic FC, Machado SAS, Avaca LA. Recent developments in electrode materials for water electrolysis. Int J Hydrogen Energy $2000 ; 25: 415-423$.

[17] Divisek J, Schmitz H, Steffen B. Electrocatalyst Materials for Hydrogen Evolution. Electrochim Acta 1994;39:1723-1731.

[18] Herraiz-Cardona I, Ortega E, Pérez-Herranz V. Impedance study of hydrogen evolution on $\mathrm{Ni} / \mathrm{Zn}$ and $\mathrm{Ni}-\mathrm{Co} / \mathrm{Zn}$ stainless steel based electrodeposits. Electrochim Acta 2011;56:1308-1315.

[19] García-Antón J, Blasco-Tamarit E, García-García DM, Guiñón-Pina V, LeivaGarcía R, Pérez-Herranz V. 2008: P200803389.

[20] Dini JW. Electrodeposition: the materials science of coatings and substrates, Noyes Publications 1993, p. 46-89.

[21] Borucinski T, Rausch S, Wendt H. Raney-Nickel Activated $\mathrm{H}_{2}$-Cathodes.2. Correlation of Morphology and Effective Catalytic Activity of Raney-Nickel Coated Cathodes. J Appl Electrochem 1992;22:1031-1038.

[22] Navarro-Flores E, Chong ZW, Omanovic S. Characterization of Ni, NiMo, NiW and $\mathrm{NiFe}$ electroactive coatings as electrocatalysts for hydrogen evolution in an acidic medium. J Mol Cat A: Chemical 2005;226:179-197.

[23] Southampton Electrochemistry Group. Instrumental Methods in Electrochemistry. New York: Wiley; 1985. 
[24] Chen LL, Lasia A. Hydrogen evolution reaction on Nickel-Molybdenum powder Electrodes. J Electrochem Soc 1992;139:3458-3464.

[25] J. O. Bockris and A. K. N. Reddy. Modern Electrochemistry. $2^{\text {nd }}$ ed. New York: Kluwer/Plenum Press; 2000.

[26] Rami A, Lasia A. Kinetics of hydrogen evolution on Ni-Al Alloy electrodes. J Appl Electrochem 1992;22:376-382.

[27] Los P, Rami A, Lasia A. Hydrogen evolution reaction on Ni-Al electrodes. J Appl Electrochem 1993;23:135-140.

[28] Kubisztal J, Budniok A, Lasia A. Study of the hydrogen evolution reaction on nickel-based composite coatings containing molybdenum power. Int J Hydrogen Energy 2007;32:1211-1218.

[29] Angelo ACD, Lasia A. Surface effects in the hydrogen evolution reaction on NiZn Alloy electrodes in alkaline-solutions. J Electrochem Soc 1995;142:3313-3319.

[30] Highfield JG, Claude E, Oguro K. Electrocatalytic synergism in Ni/Mo cathodes for hydrogen evolution in acid medium: a new model. Electrochim Acta 1999;44:2805-2814.

[31] Kaninski MPM, Nikolic VM, Potkonjak TN, SimonoviccBR, Potkonjak NI. Catalytic activity of Pt-based intermetallics for the hydrogen production Influence of ionic activator. Appl Cat A: General 2007;321:93-99.

[32] Metikos-Hukovic A, Grubac Z, Radic N, Tonejc A. Sputter deposited nanocrystalline $\mathrm{Ni}$ and $\mathrm{Ni}-\mathrm{W}$ films as catalysts for hydrogen evolution. J Mol Cat A: Chemical 2006;249:172-180.

[33] Rosalbino F, Delsante S, Borzone G, Angelini E. Electrocatalytic behaviour of Co-Ni-R ( $\mathrm{R}=$ Rare earth metal) crystalline alloys as electrode materials for hydrogen evolution reaction in alkaline medium. Int $\mathbf{J}$ Hydrogen Energy 2008;33:6696-6703. 
[34] Dominquez-Crespo MA, Ramirez-Meneses E, Montiel-Palma V, Huerta AMT, Rosales HD. Synthesis and electrochemical characterization of stabilized nickel nanoparticles. Int J Hydrogen Energy 2009;34:1664-1676.

[35] Kawashima A, Akiyama E, Habazaki H, Hashimoto K. Characterization of sputter-deposited Ni-Mo and Ni-W alloy electrocatalysts for hydrogen evolution in alkaline solution. Mat Sci \& Eng A 1997;226-228:905-909.

[36] Krstajic N, Trasatti S. Cathodic behaviour of $\mathrm{RuO}_{2}$-doped $\mathrm{Ni} / \mathrm{Co}_{3} \mathrm{O}_{4}$ electrodes in alkaline solutions: hydrogen evolution. J Appl Electrochem 1998;28:1291-1297.

[37] Marozzi CA, Chialvo AC. Development of electrode morphologies of interest in electrocatalysis: Part 2: Hydrogen evolution reaction on macroporous nickel electrodes. Electrochim Acta 2001;46:861-866.

[38] Kellenberger A, Vaszilcsin N, Brandl W, Duteanu N. Kinetics of hydrogen evolution reaction on skeleton nickel and nickel-titanium electrodes obtained by thermal arc spraying technique. Int J Hydrogen Energy 2007;32:3258-3265.

[39] Shervedani RK, Madram AR. Electrocatalytic activities of nanocomposite $\mathrm{Ni}_{81} \mathrm{P}_{16} \mathrm{C}_{3}$ electrode for hydrogen evolution reaction in alkaline solution by electrochemical impedance spectroscopy. Int J Hydrogen Energy 2008;33:24682476.

[40] Herraiz-Cardona I, Ortega E, García Antón J, Pérez-Herranz V. Assessment of the roughness factor effect and the intrinsic catalytic activity for hydrogen evolution reaction on Ni-based electrodeposits. Int $\mathrm{J}$ Hydrogen Energy 2011; doi:10.1016/j.ijhydene.2011.05.047.

[41] Armstrong RD, Henderson M. Impedance plane display of a reaction with an adsorbed intermediate. J Electroanal Chem 1972;39:81-90.

[42] Simpraga R, Tremiliosi-Filho G, Qian SY, Conway BE. In situ determination of the 'real are factor' in $\mathrm{H}_{2}$ evolution electrocatalysis at porous Ni---Fe composite electrodes. J Electroanal Chem 1997;424:141-151. 
[43] Castro EB, Giz MJ, Gonzalez ER, Vilche JR. An electrochemical impedance study on the kinetics and mechanism of the hydrogen evolution reaction on nickel molybdenite electrodes. Electrochim Acta 1997;42:951-959.

[44] Brug GJ, Vandeneeden ALG, Sluytersrehbach M, Sluyters JH. The analysis of electrode impedances complicated by the presence of a constant phase element. J Electroanal Chem 1984;176:275-295.

[45] Trasatti S, Petrii OA. Real Surface-Area Measurements in Electrochemistry. Pure Appl Chem 1991;63:711-734.

[46] Rausch S, Wendt H. Morphology and utilization of smooth hydrogen-evolving raney nickel cathode coatings and porous sintered-nickel cathodes. J Electrochem Soc 1996;143:2852-2862.

[47] Pierozynski B, Smoczynski L. Kinetics of hydrogen evolution reaction at NickelCoated carbon fiber materials in $0.5 \mathrm{M} \mathrm{H}_{2} \mathrm{SO}_{4}$ and $0.1 \mathrm{M} \mathrm{NaOH}$ solutions. J Electrochem Soc 2009;156:B1045-B1050.

[48] Ganesh V, Lakshminarayanan V. Preparation of high surface area nickel electrodeposit using a liquid crystal template technique. Electrochim Acta 2004;49:3561-3572.

[49] Lupi C, Dell'Era A, Pasquali M. Nickel-cobalt electrodeposited alloys for hydrogen evolution in alkaline media. Int J Hydrogen Energy 2009;34:2101-2106.

[50] Yazici B, Tatli G, Galip H, Erbil M. Investigation of suitable cathodes for the production of hydrogen gas by electrolysis. Int J Hydrogen Energy 1995;20:957965.

[51] LeRoy RL. Industrial water electrolysis: Present and future. Int J Hydrogen Energy 1983;8:401-417.

[52] LeRoy RL, Bowen CT, Leroy DJ. The thermodynamics of aqueous water electrolysis. J Electrochem Soc 1980;127:1954-1962. 
[53] Divisek J. Water electrolysis in a low and medium temperature regime, in: $\mathrm{H}$. Wendt, editors. Electrochemical production and combustion of hydrogen, Elsevier Publishing Company; 1990, p.137-212.

[54] Sherif SA, Barbir F, Veziroglu TN. Wind energy and the hydrogen economy-review of the technology. Sol Energy 2005;78:647-660. 


\section{LIST OF TABLES}

Table 1. Bath composition used in the electrodeposition of electrocatalytic coatings on an AISI 304 stainless steel substrate.

Table 2. Kinetic parameters of the HER obtained from the polarization curves recorded in $30 \% \mathrm{wt} \mathrm{KOH}$ solution at different temperatures.

Table 3. EEC parameters of the 2TP model obtained by fitting EIS experimental spectra recorded in $30 \%$ wt. $\mathrm{KOH}$ solution at various overpotentials and at $80{ }^{\circ} \mathrm{C}$ on the $\mathrm{NiCo} / \mathrm{Zn}$ coating.

Table 4. Experimental discharge potentials $\left(E_{\text {exp }}\right)$ and overpotentials $\left(\eta_{\text {exp }}\right)$ obtained from the $\mathrm{H}_{2}$ discharge curves recorded in $30 \%$ wt. $\mathrm{KOH}$ solution at different temperatures. 


\section{LIST OF FIGURES}

Figure 1. Electrochemical cell (P200803389) and electrical connections.

Figure 2. Confocal Laser Scanning micrograph of the $\mathrm{NiCo} / \mathrm{Zn}$ catalyst after the alkaline leaching.

Figure 3. Linear Tafel polarization curves recorded on $\mathrm{NiCo} / \mathrm{Zn}$ (solid symbols), and smooth $\mathrm{Ni}$ (open symbols) electrocatalysts in $30 \% \mathrm{wt}$. $\mathrm{KOH}$ solution at: $\circ 30^{\circ} \mathrm{C}, \triangle 50$ ${ }^{\circ} \mathrm{C}, \square 80{ }^{\circ} \mathrm{C}$.

Figure 4. Nyquist representation of the impedance data obtained for the $\mathrm{NiCo} / \mathrm{Zn}$ catalyst in $30 \%$ wt. $\mathrm{KOH}$ solution at: a) $80^{\circ} \mathrm{C}$ (effect of overpotential); and b) $\eta_{2}$ (effect of temperature). Symbols are the experimental points and solid lines are modelled data.

Figure 5. Two-time constants parallel model (2TP) used to explain the EIS response of the HER on the $\mathrm{NiCo} / \mathrm{Zn}$ electrode.

Figure 6. Surface roughness factor, $R_{f}$, as a function of the overpotential for the $\mathrm{NiCo} / \mathrm{Zn}$ electrode in $30 \%$ wt. $\mathrm{KOH}$ solution at: $\circ 30^{\circ} \mathrm{C}, \triangle 50{ }^{\circ} \mathrm{C}, \square 80^{\circ} \mathrm{C}$.

Figure 7. Linear Tafel polarization curves recorded on $\mathrm{NiCo} / \mathrm{Zn}$ (solid symbols), and smooth $\mathrm{Ni}$ (open symbols) electrocatalysts in $30 \%$ wt. $\mathrm{KOH}$ solution, corrected considering the surface roughness factor, $R_{f}$, at: $\circ 30^{\circ} \mathrm{C}, \triangle 50{ }^{\circ} \mathrm{C}, \square 80^{\circ} \mathrm{C}$.

Figure 8. Hydrogen discharge curves recorded on $\mathrm{NiCo} / \mathrm{Zn}$, and smooth $\mathrm{Ni}$ electrocatalysts in $30 \%$ wt. $\mathrm{KOH}$ solution at $30^{\circ} \mathrm{C}$.

Figure 9. Effect of temperature on the maximum efficiency of $\mathrm{NiCo} / \mathrm{Zn}$ (solid symbols), and smooth $\mathrm{Ni}$ (open symbols) electrocatalysts in $30 \% \mathrm{wt}$. KOH solution.

Figure 10. a) Effect of applied current density on the cell voltage and the hydrogen production for the $\mathrm{NiCo} / \mathrm{Zn}$ electrocatalyst at $50{ }^{\circ} \mathrm{C}$. b) Effect of temperature on the cell voltage and the hydrogen production for the $\mathrm{NiCo} / \mathrm{Zn}$ electrocatalyst at $50 \mathrm{~mA} \mathrm{~cm}$. 
Figure 11. 3-D diagram of the energy consumption per $1 \mathrm{~mol}$ of $\mathrm{H}_{2}$ produced. Comparison between the smooth pure $\mathrm{Ni}$ and $\mathrm{NiCo} / \mathrm{Zn}$ cathodes.

Figure 12. 3-D diagram of the efficiency. Comparison between the smooth pure Ni and $\mathrm{NiCo} / \mathrm{Zn}$ cathodes. 
Table 1. Bath composition used in the electrodeposition of electrocatalytic coatings on an AISI 304 stainless steel substrate.

Catalyst

$\mathrm{NiCo} / \mathrm{Zn}$

Composition ( $\left.\mathrm{g} \mathrm{L}^{-1}\right)$

$\mathrm{NiSO}_{4} \cdot 6\left(\mathrm{H}_{2} \mathrm{O}\right) \quad 300$

$\mathrm{NiCl}_{2} \cdot 6\left(\mathrm{H}_{2} \mathrm{O}\right)$

$\mathrm{H}_{3} \mathrm{BO}_{3}$

$\mathrm{ZnCl}_{2}$

$\mathrm{CoSO}_{4} \cdot 6\left(\mathrm{H}_{2} \mathrm{O}\right)$ 
Table 2. Kinetic parameters of the HER obtained from the polarization curves recorded in $30 \% \mathrm{wt} \mathrm{KOH}$ solution at different temperatures.

\begin{tabular}{|c|c|c|c|c|c|c|}
\hline \multirow[t]{2}{*}{ Catalyst } & \multicolumn{6}{|c|}{ Temperature $\left({ }^{\circ} \mathrm{C}\right)$} \\
\hline & 30 & 40 & 50 & 60 & 70 & 80 \\
\hline \multicolumn{7}{|l|}{ Smooth Ni } \\
\hline$b_{l \eta}\left(\mathrm{mV} \operatorname{dec}^{-1}\right)$ & 255.7 & 235.6 & 240.3 & 223.6 & 256.3 & 249.8 \\
\hline$b_{h \eta}\left(\mathrm{mV} \operatorname{dec}^{-1}\right)$ & 97.9 & 103.7 & 107.5 & 122.8 & 137.3 & 171.4 \\
\hline$i_{0}\left(\mu \mathrm{A} \mathrm{cm}^{-2}\right)$ & 0.07 & 0.16 & 0.44 & 0.92 & 2.00 & 4.77 \\
\hline$\beta$ & 0.61 & 0.60 & 0.60 & 0.54 & 0.50 & 0.41 \\
\hline$\eta_{100}(\mathrm{mV})$ & 503 & 496 & 470 & 496 & 502 & 555 \\
\hline \multicolumn{7}{|l|}{$\mathrm{NiCo} / \mathrm{Zn}$} \\
\hline$b\left(\mathrm{mV} \operatorname{dec}^{-1}\right)$ & 81.1 & 87.1 & 94.1 & 105.5 & 111.9 & 120.3 \\
\hline$i_{0}\left(\mathrm{~mA} \mathrm{~cm}^{-2}\right)$ & 3.3 & 5.4 & 7.9 & 12.8 & 20.63 & 28.27 \\
\hline$\beta$ & 0.77 & 0.69 & 0.68 & 0.63 & 0.61 & 0.58 \\
\hline$\eta_{100}(\mathrm{mV})$ & 119.6 & 109.1 & 104.0 & 94.2 & 76.7 & 66 \\
\hline
\end{tabular}


Table 3. EEC parameters of the $2 \mathrm{TP}$ model obtained by fitting EIS experimental spectra recorded in $30 \% \mathrm{wt}$. $\mathrm{KOH}$ solution at various overpotentials and at $80{ }^{\circ} \mathrm{C}$ on the $\mathrm{NiCo} / \mathrm{Zn}$ coating.

\begin{tabular}{|c|c|c|c|c|}
\hline \multirow[t]{2}{*}{ Parameter } & \multicolumn{4}{|c|}{ Overpotential } \\
\hline & $\eta_{1}(=0 \mathrm{mV})$ & $\eta_{2}(=19.3 \mathrm{mV})$ & $\eta_{3}(=34.7 \mathrm{mV})$ & $\eta_{4}(=71.9 \mathrm{mV})$ \\
\hline$\chi^{2}$ & $1.51 \cdot 10^{-4}$ & $6.30 \cdot 10^{-5}$ & $1.04 \cdot 10^{-4}$ & $1.03 \cdot 10^{-4}$ \\
\hline$R_{S}\left(\Omega \mathrm{cm}^{2}\right)$ & 0.40 & 0.41 & 0.41 & 0.41 \\
\hline$R_{l}\left(\Omega \mathrm{cm}^{2}\right)$ & 1.30 & 0.52 & 0.35 & 0.32 \\
\hline$R_{2}\left(\Omega \mathrm{cm}^{2}\right)$ & 36.03 & 6.60 & 1.42 & 0.15 \\
\hline$Q_{1}\left(\Omega^{-1} \mathrm{~cm}^{-2} \mathrm{~s}^{\mathrm{n}}\right)$ & 0.425 & 0.353 & 0.270 & 0.190 \\
\hline$n_{1}$ & 0.91 & 0.90 & 0.89 & 0.91 \\
\hline$C_{1}\left(\mathrm{~F} \mathrm{~cm}^{-2}\right)^{*}$ & 0.348 & 0.270 & 0.188 & 0.138 \\
\hline$C_{2}\left(\mathrm{~F} \mathrm{~cm}^{-2}\right)$ & 2.39 & 2.41 & 3.03 & 5.88 \\
\hline
\end{tabular}


Table 4. Experimental discharge potentials $\left(E_{\text {exp }}\right)$ and overpotentials $\left(\eta_{\text {exp }}\right)$ obtained from the $\mathrm{H}_{2}$ discharge curves recorded in $30 \%$ wt. $\mathrm{KOH}$ solution at different temperatures.

\begin{tabular}{|c|c|c|c|c|c|c|c|}
\hline \multicolumn{2}{|l|}{ Catalyst } & \multicolumn{6}{|c|}{ Temperature $\left({ }^{\circ} \mathrm{C}\right)$} \\
\hline & & 30 & 40 & 50 & 60 & 70 & 80 \\
\hline \multicolumn{8}{|c|}{ Smooth Ni } \\
\hline & $E_{\text {exp }}(\mathrm{V})$ & 1.830 & 1.820 & 1.810 & 1.801 & 1.794 & 1.780 \\
\hline & $\eta_{\exp }(\mathrm{V})$ & 0.605 & 0.603 & 0.602 & 0.601 & 0.602 & 0.596 \\
\hline \multicolumn{8}{|c|}{$\mathrm{NiCo} / \mathrm{Zn}$} \\
\hline & $E_{\text {exp }}(\mathbf{V})$ & 1.620 & 1.600 & 1.581 & 1.570 & 1.560 & 1.551 \\
\hline & $\eta_{\exp }(\mathrm{V})$ & 0.395 & 0.383 & 0.373 & 0.370 & 0.368 & 0.367 \\
\hline
\end{tabular}




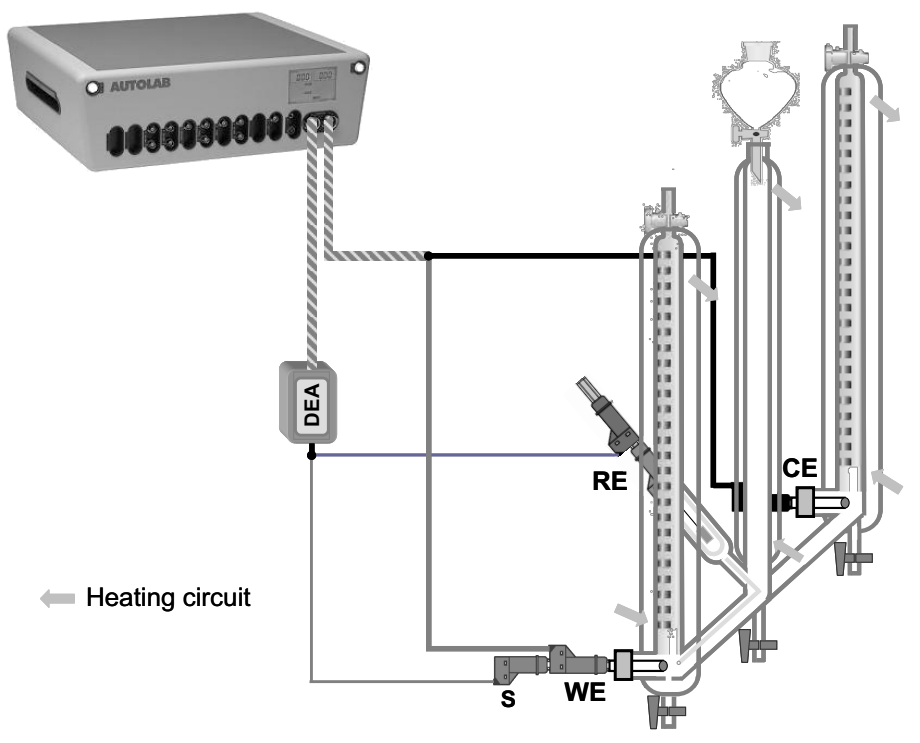

Figure 1. Electrochemical cell (P200803389) and electrical connections. 


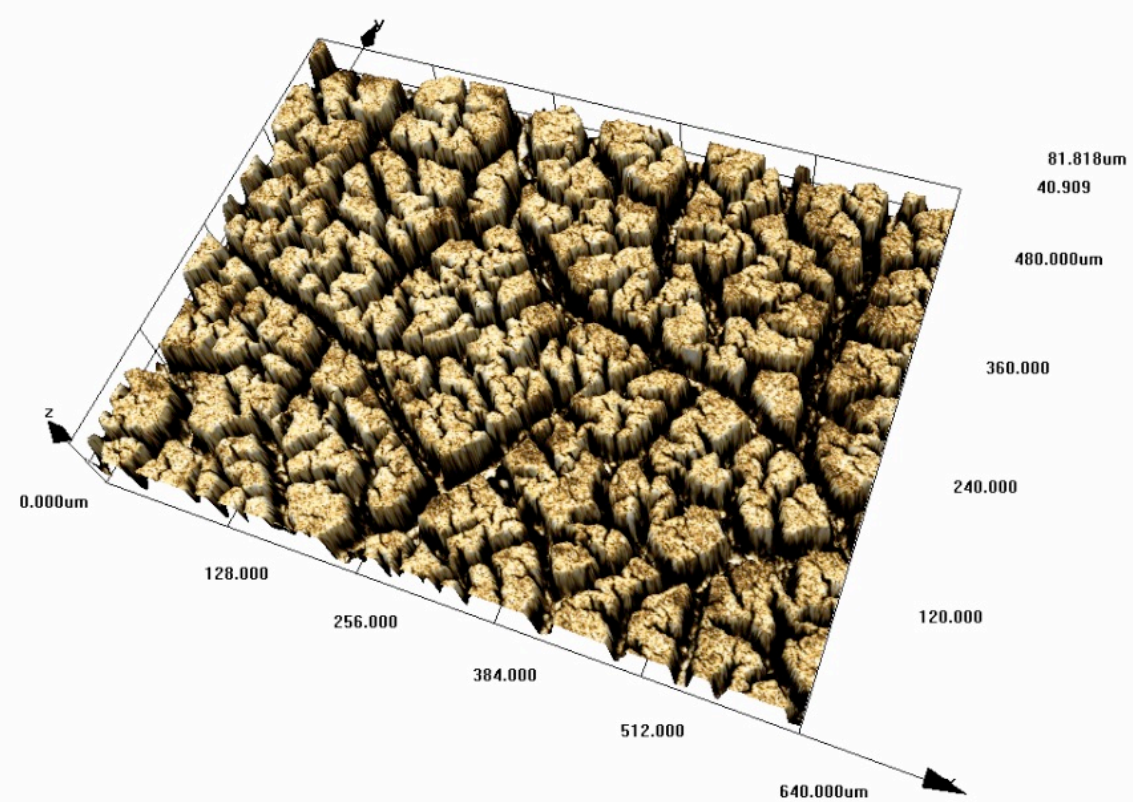

Figure 2. Confocal Laser Scanning micrograph of the $\mathrm{NiCo} / \mathrm{Zn}$ catalyst after the alkaline leaching. 


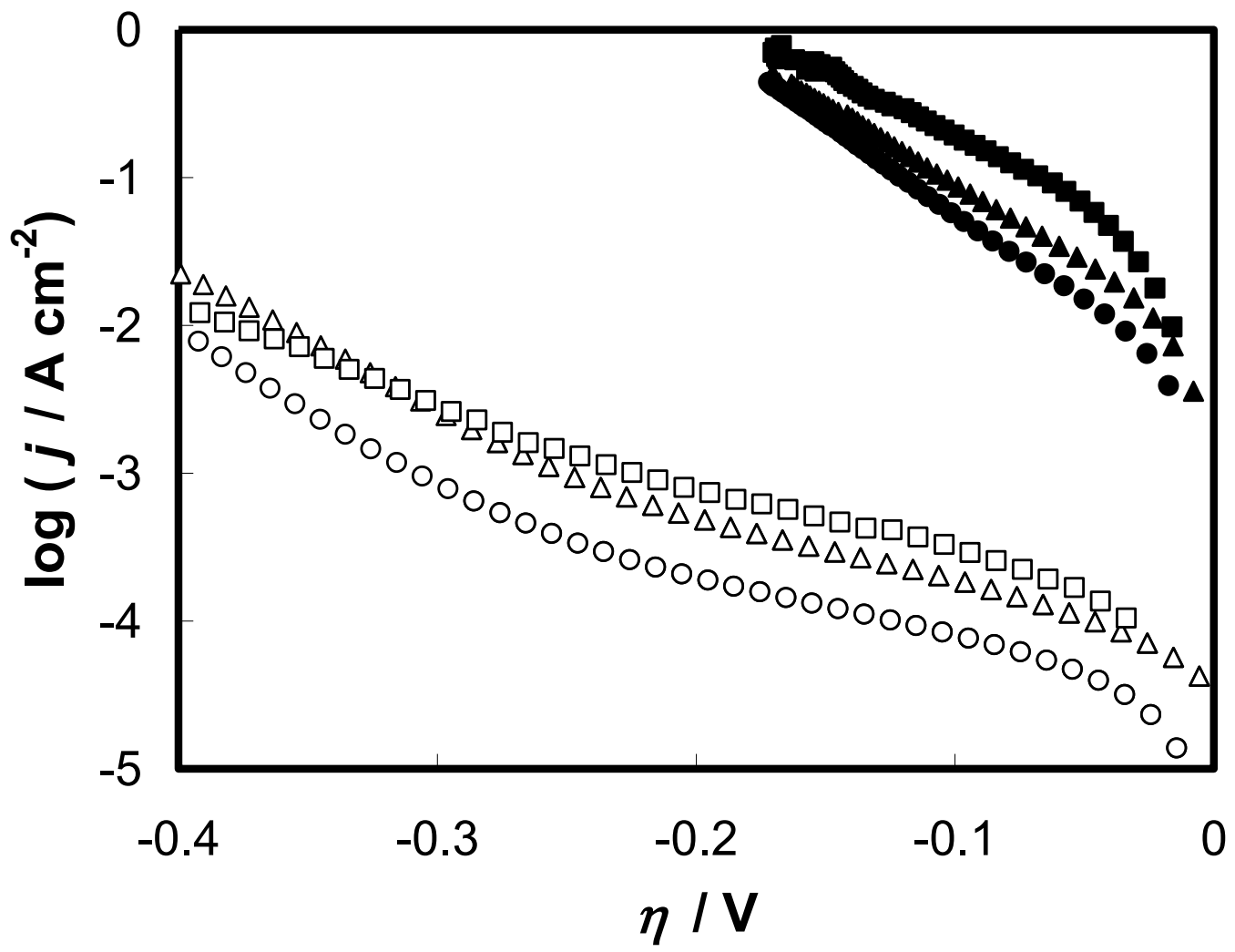

Figure 3. Linear Tafel polarization curves recorded on $\mathrm{NiCo} / \mathrm{Zn}$ (solid symbols), and smooth Ni (open symbols) electrocatalysts in $30 \% \mathrm{wt}$. KOH solution at: $\circ 30^{\circ} \mathrm{C}, \triangle 50$ ${ }^{\circ} \mathrm{C}, \square 80^{\circ} \mathrm{C}$. 
a)

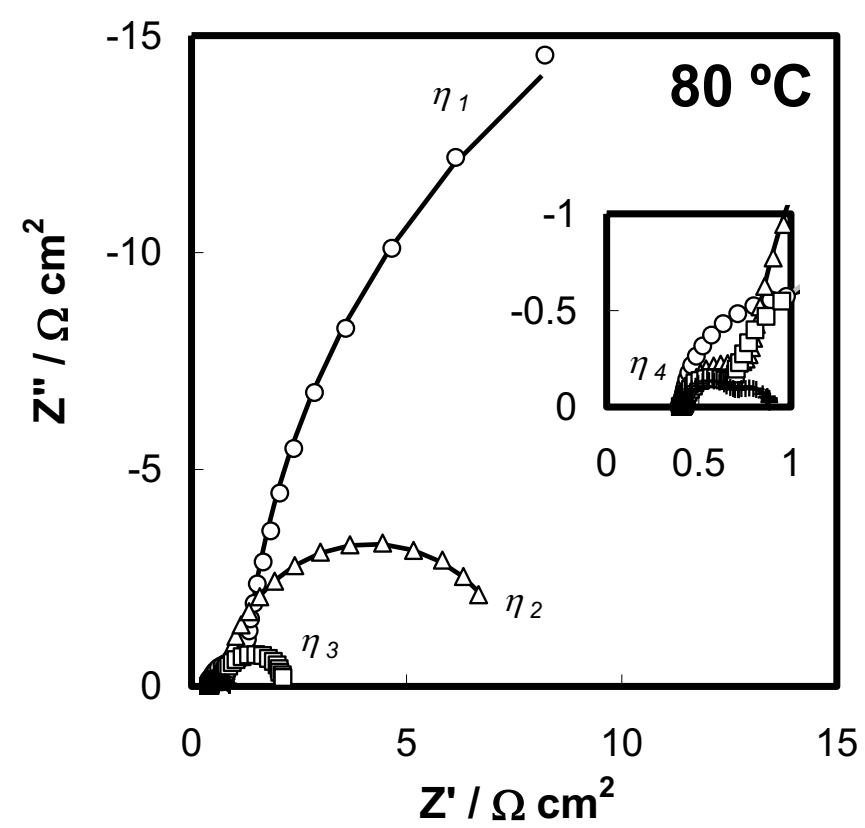

b)

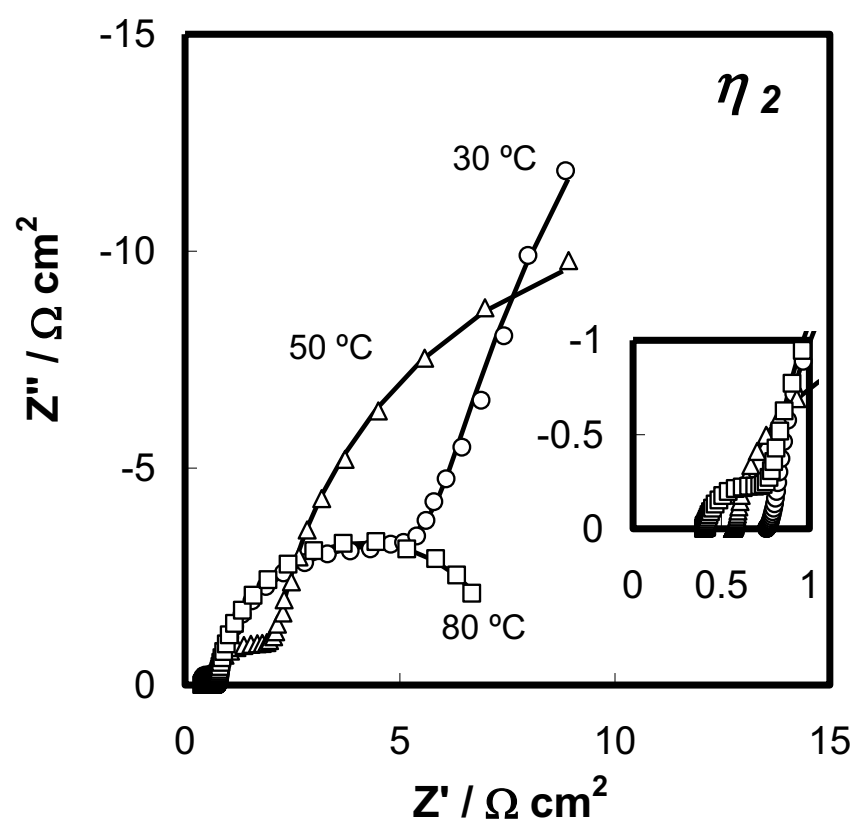

Figure 4. Nyquist representation of the impedance data obtained for the $\mathrm{NiCo} / \mathrm{Zn}$ catalyst in $30 \%$ wt. $\mathrm{KOH}$ solution at: a) $80{ }^{\circ} \mathrm{C}$ (effect of overpotential); and b) $\eta_{2}$ (effect of temperature). Symbols are the experimental points and solid lines are modelled data. 


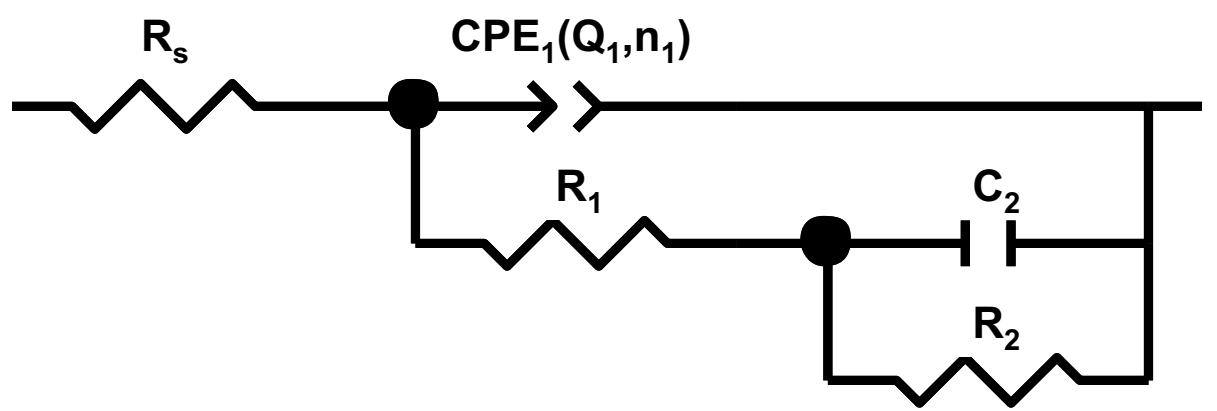

Figure 5. Two-time constants parallel model (2TP) used to explain the EIS response of the HER on the $\mathrm{NiCo} / \mathrm{Zn}$ electrode. 


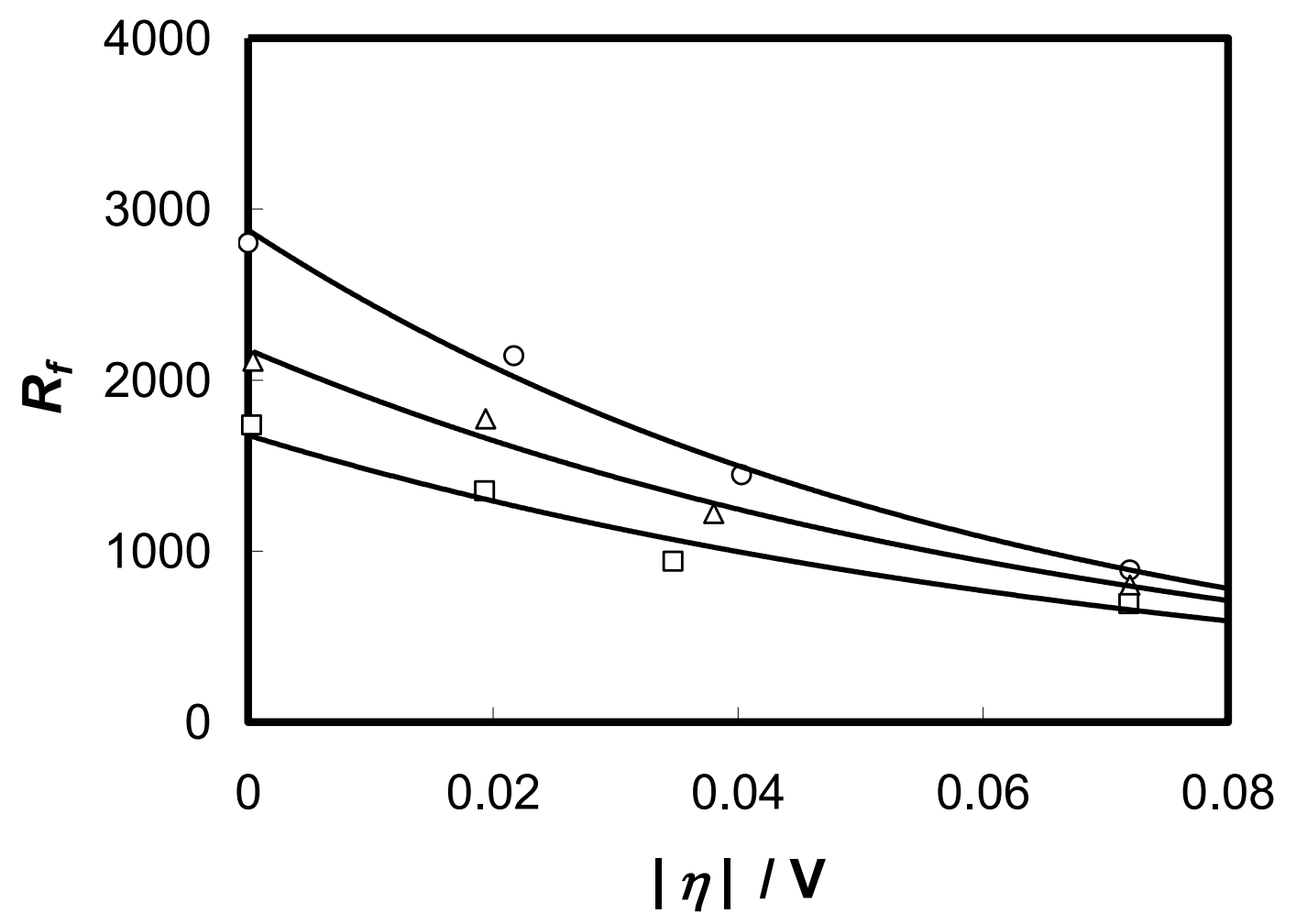

Figure 6. Surface roughness factor, $R_{f}$, as a function of the overpotential for the $\mathrm{NiCo} / \mathrm{Zn}$ electrode in $30 \% \mathrm{wt}$. $\mathrm{KOH}$ solution at: $\circ 30^{\circ} \mathrm{C}, \triangle 50^{\circ} \mathrm{C}, \square 80^{\circ} \mathrm{C}$. 


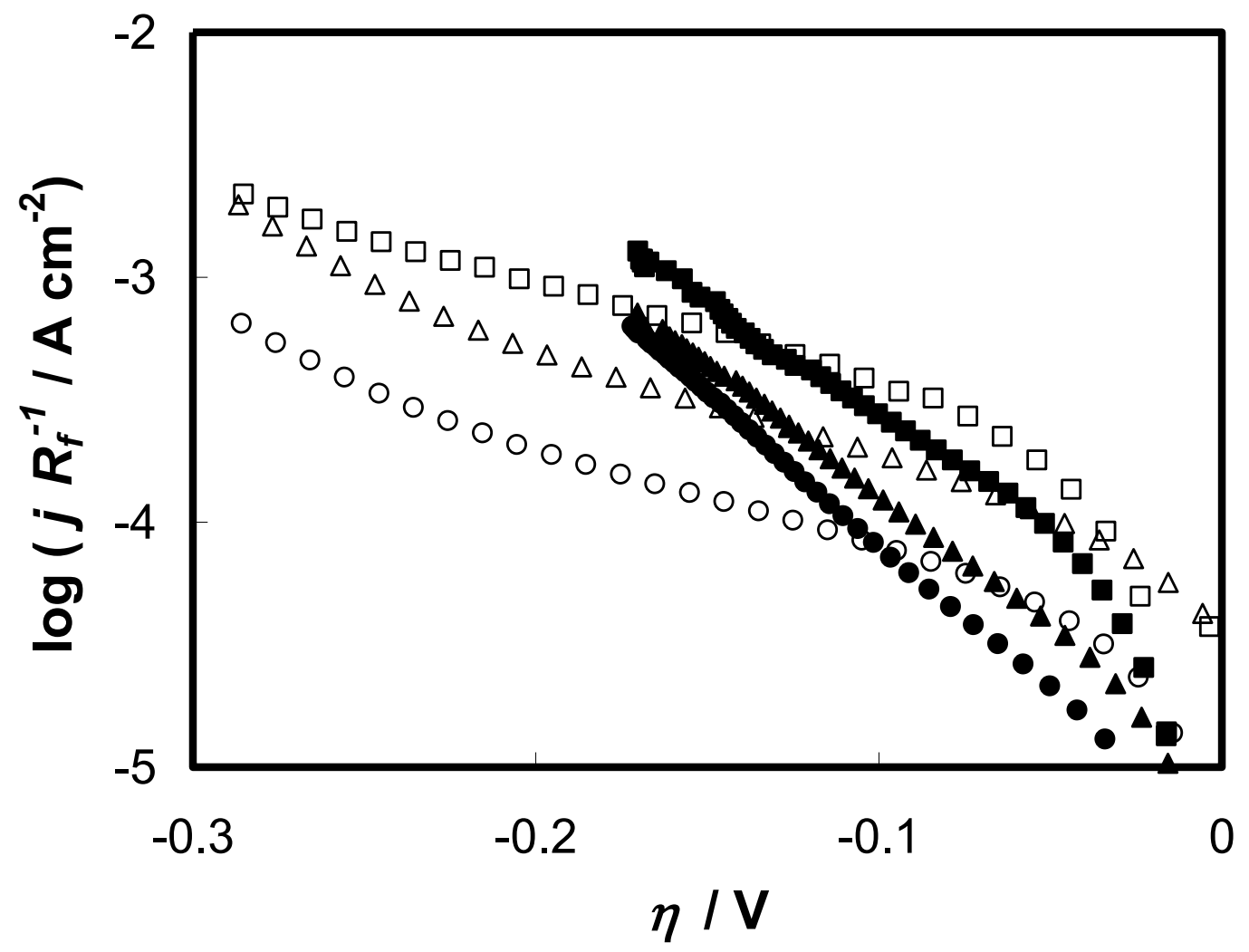

Figure 7. Linear Tafel polarization curves recorded on $\mathrm{NiCo} / \mathrm{Zn}$ (solid symbols), and smooth $\mathrm{Ni}$ (open symbols) electrocatalysts in $30 \%$ wt. $\mathrm{KOH}$ solution, corrected considering the surface roughness factor, $R_{f}$, at: $\circ 30^{\circ} \mathrm{C}, \triangle 50{ }^{\circ} \mathrm{C}, \square 80^{\circ} \mathrm{C}$. 


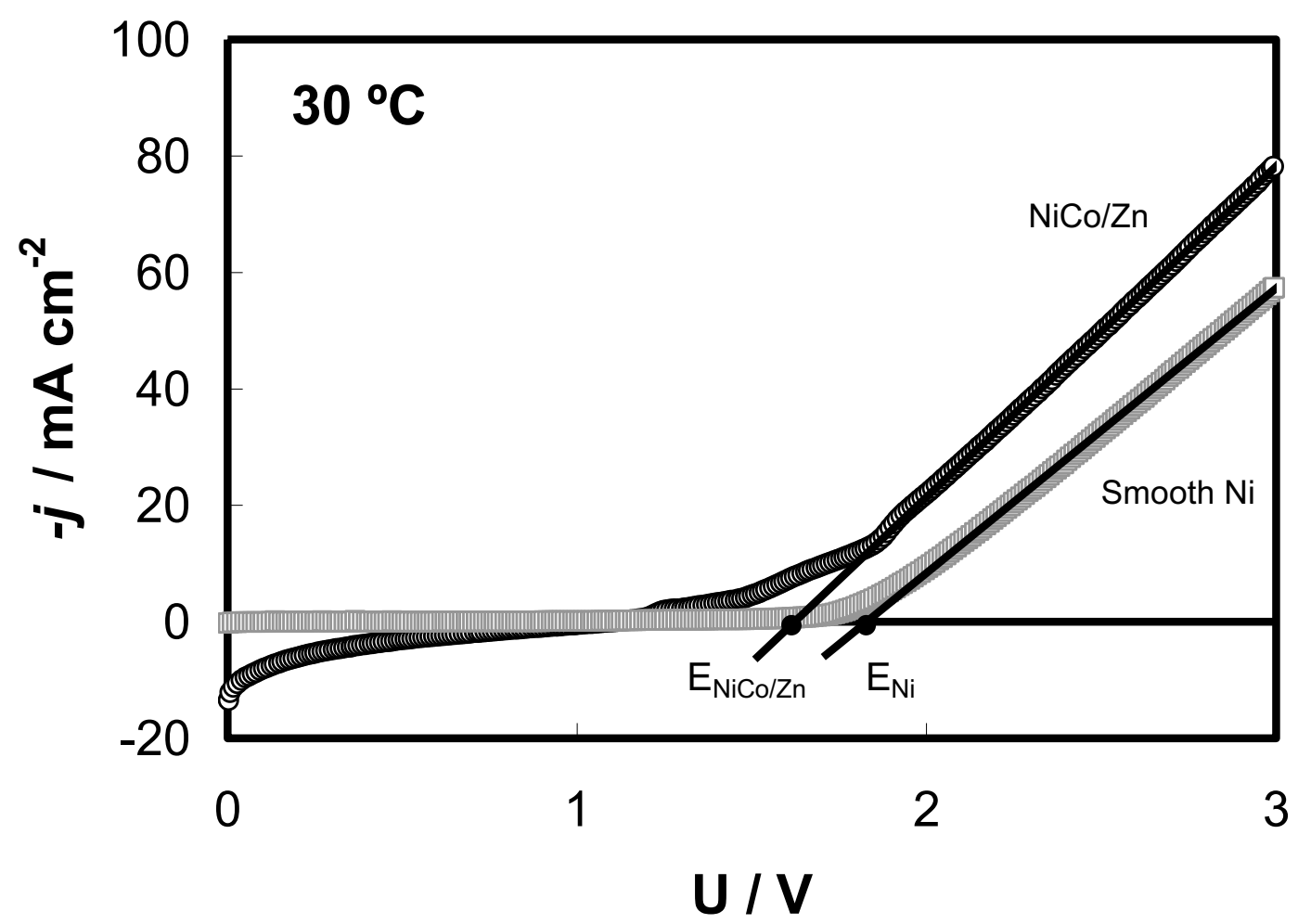

Figure 8. Hydrogen discharge curves recorded on $\mathrm{NiCo} / \mathrm{Zn}$, and smooth $\mathrm{Ni}$ electrocatalysts in $30 \%$ wt. $\mathrm{KOH}$ solution at $30^{\circ} \mathrm{C}$. 


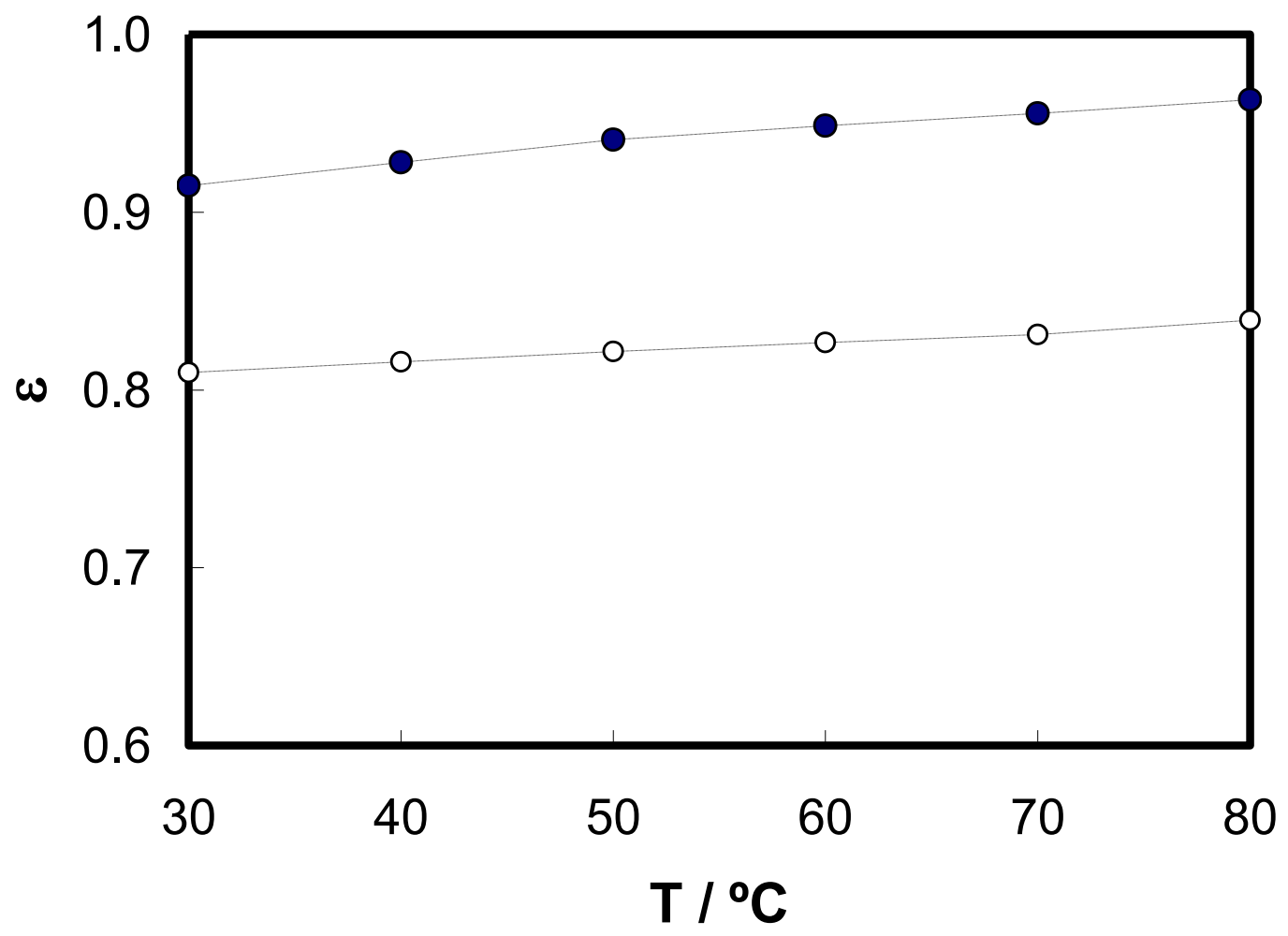

Figure 9. Effect of temperature on the maximum efficiency of $\mathrm{NiCo} / \mathrm{Zn}$ (solid symbols), and smooth $\mathrm{Ni}$ (open symbols) electrocatalysts in $30 \% \mathrm{wt}$. KOH solution. 
a)

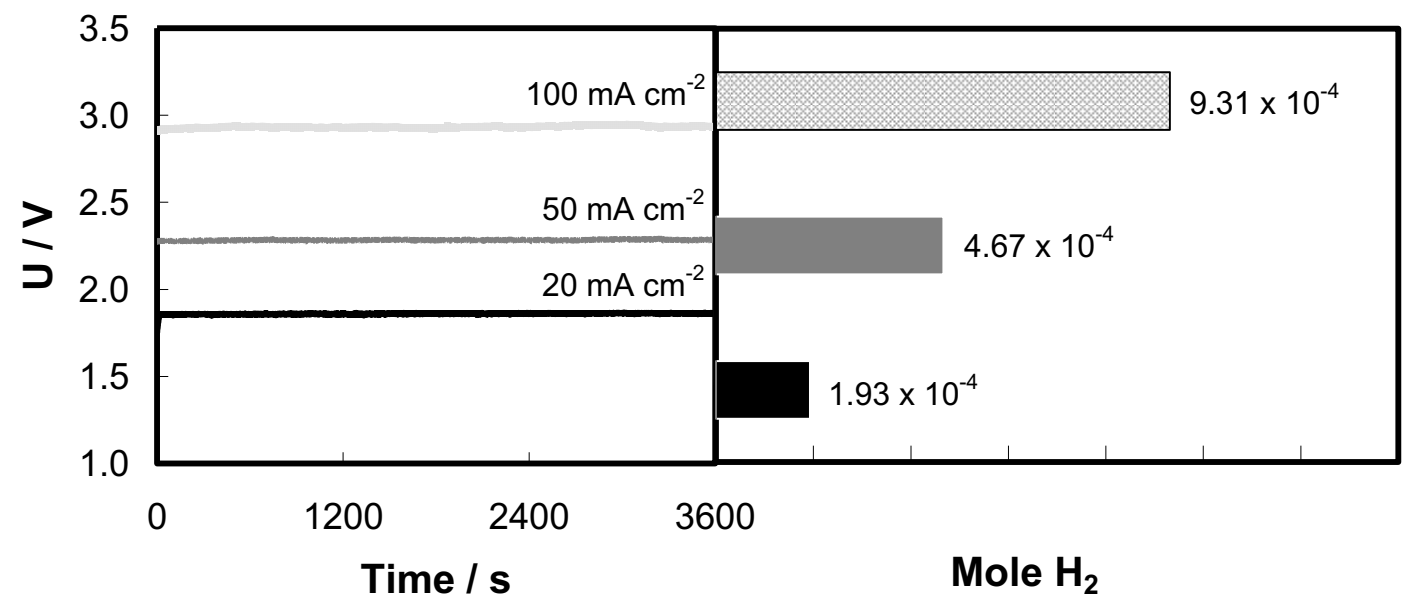

b)

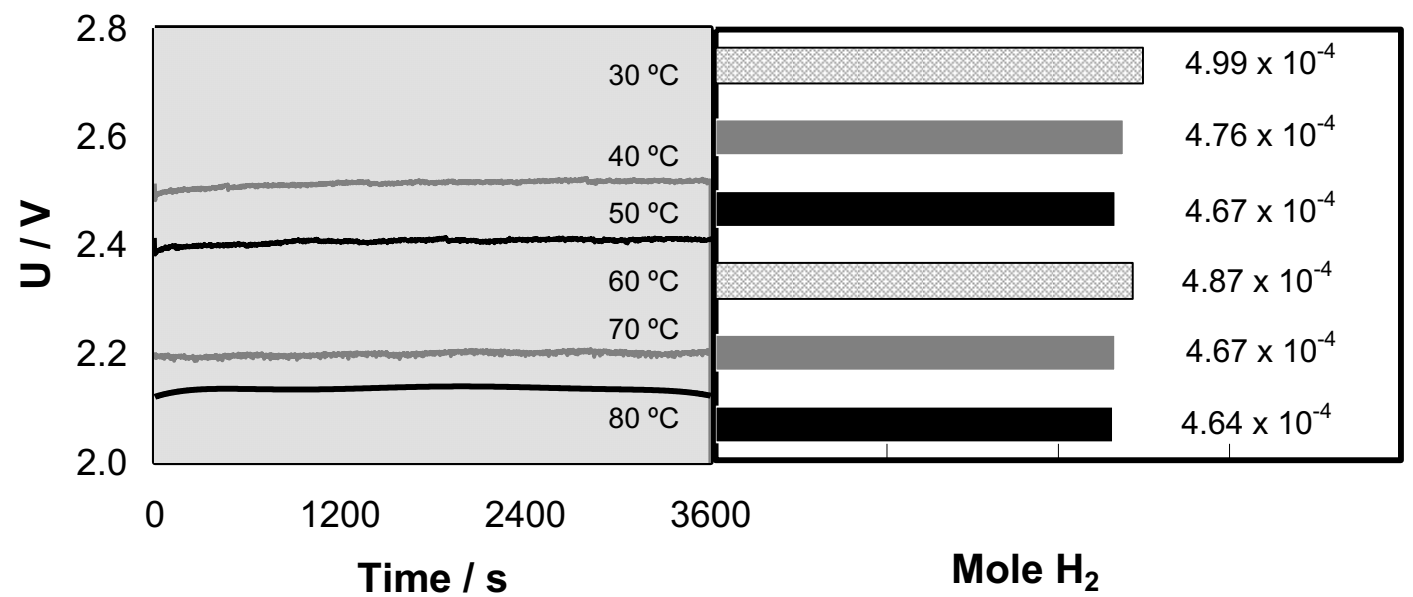

Figure 10. a) Effect of applied current density on the cell voltage and the hydrogen production for the $\mathrm{NiCo} / \mathrm{Zn}$ electrocatalyst at $50^{\circ} \mathrm{C}$. b) Effect of temperature on the cell voltage and the hydrogen production for the $\mathrm{NiCo} / \mathrm{Zn}$ electrocatalyst at $50 \mathrm{~mA} \mathrm{~cm}$. 


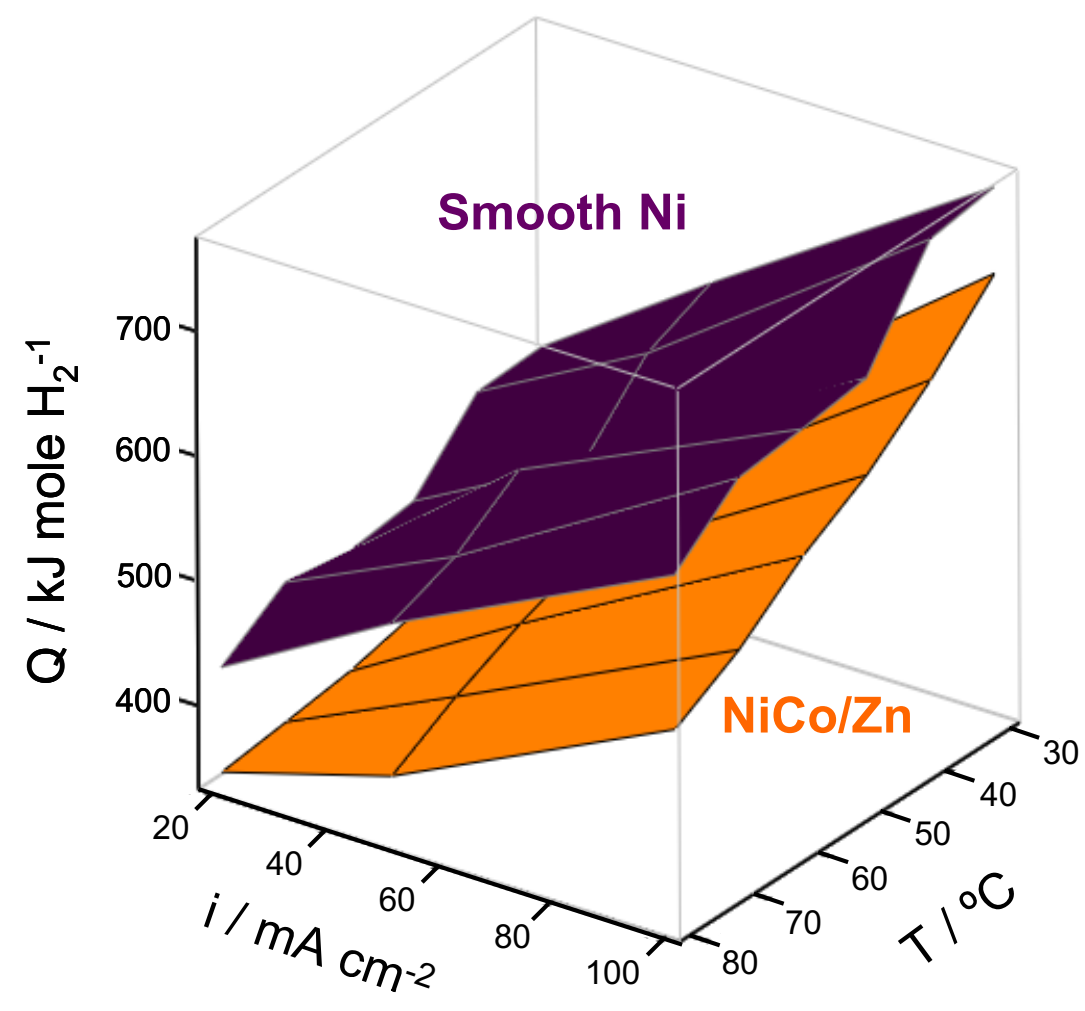

Figure 11. 3-D diagram of the energy consumption per 1 mol of $\mathrm{H}_{2}$ produced.

Comparison between the smooth pure $\mathrm{Ni}$ and $\mathrm{NiCo} / \mathrm{Zn}$ cathodes. 


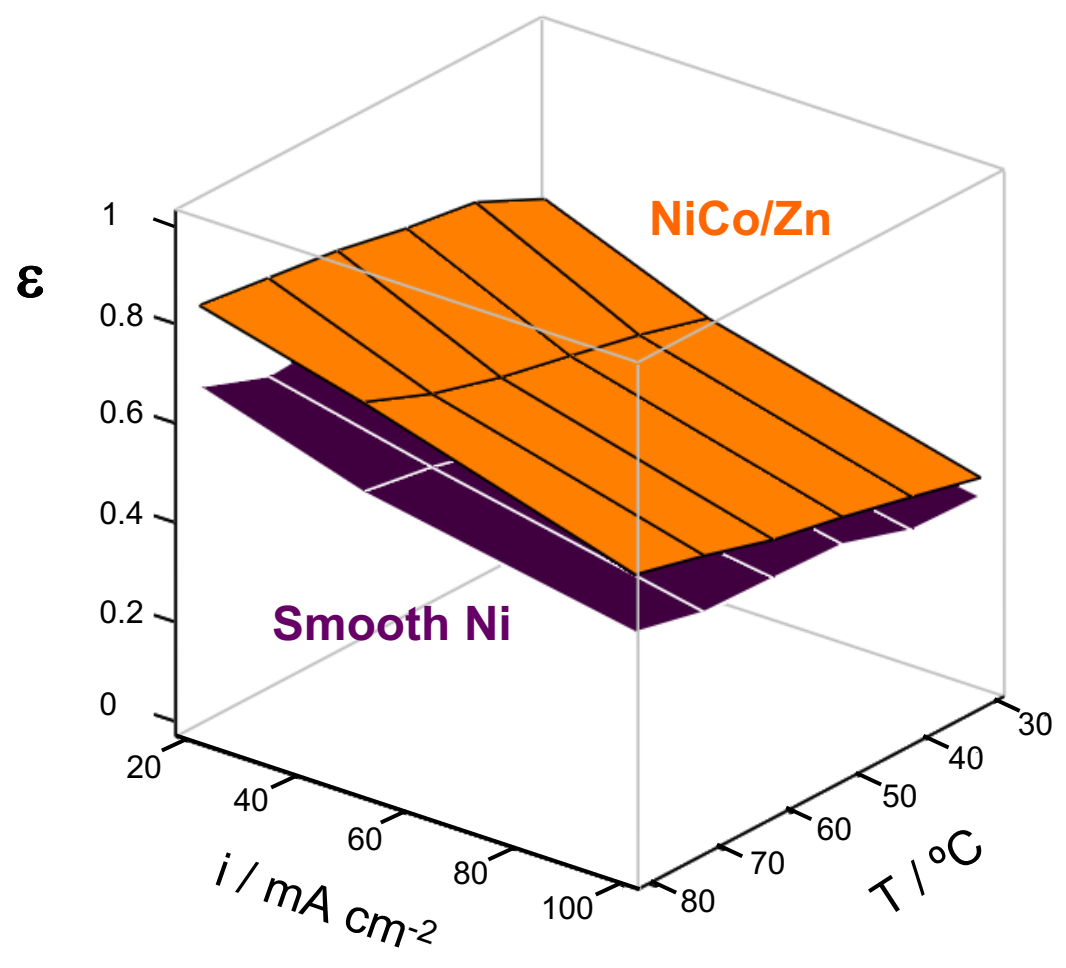

Figure 12. 3-D diagram of the efficiency. Comparison between the smooth pure $\mathrm{Ni}$ and $\mathrm{NiCo} / \mathrm{Zn}$ cathodes. 